\title{
Local abundance, apparent survival and site fidelity of Bryde's whales in the Hauraki Gulf (New Zealand) inferred from long-term photo-identification
}

\author{
G. Tezanos-Pinto ${ }^{1, *}$, K. Hupman' ${ }^{1}$, N. Wiseman ${ }^{2}$, S. L. Dwyer ${ }^{1}$, C. S. Baker ${ }^{2,3}$, \\ L. Brooks ${ }^{4}$ B. Outhwaite ${ }^{1}$, C. Lea ${ }^{1}$, K. A. Stockin ${ }^{1}$ \\ ${ }^{1}$ Coastal-Marine Research Group, Institute of Natural and Mathematical Sciences, Massey University, Private Bag 102904, \\ North Shore, Auckland 0745, New Zealand \\ ${ }^{2}$ The University of Auckland, Private Bag 92019, Auckland 1010, New Zealand \\ ${ }^{3}$ Hatfield Marine Science Center, Oregon State University, 2030 SE Marine Science Drive, Newport, OR 97365, USA \\ ${ }^{4}$ Marine Ecology Research Centre, Southern Cross University, PO Box 157 Lismore, New South Wales 2480, Australia
}

\begin{abstract}
Bryde's whales Balaenoptera edeni in New Zealand are classified as 'nationally critical' according to the New Zealand Threat Classification System. In the Hauraki Gulf, Bryde's whales occur year-round and are subject to ship-strike mortality events. Photo-identification surveys were conducted to estimate local abundance, apparent survival and site fidelity during 2 periods from 2004 to 2006 (261 daily surveys) and from 2011 to 2013 (382 daily surveys). The photo-identification database contained a total of 364 sighting records of 72 Bryde's whales. Overall, 20 whales were sighted across the 2 survey periods, indicating long-term site fidelity. Local abundance was estimated using the robust design (RD) and POPAN mark-recapture approaches for each period, including upward adjustment for the proportion of unmarked whales. RD seasonal abundance estimates varied from 17 to 43 whales between 2004 and 2006, and from 13 to 31 whales between 2011 and 2013. Temporary emigration followed a random pattern $\left(\gamma^{\prime}=\gamma^{\prime \prime}\right)$ and was estimated at 0.557 between 2004 and 2006, and 0.610 between 2011 and 2013. POPAN seasonal abundance ranged from 38 to 74 whales for the 2004 to 2006 period and from 42 to 68 whales for 2011 to 2013. Apparent survival was estimated across periods at 0.878 (95\% CI $=0.811-0.923)$. From the 'super population' estimate of the 2011 to 2013 survey period ( $\hat{N}_{\text {super }}=135$ whales, CI $=$ 100-183), we calculated a potential biological removal (PBR) of 1 whale $\mathrm{yr}^{-1}$. Given the impact of ship strikes on this local unit, it is important to continue long-term photo-identification of Bryde's whales. This technique provides valuable demographic information for a poorly known species.
\end{abstract}

KEY WORDS: Mark-recapture $\cdot$ Pollock robust design · POPAN · Residency · Balaenoptera · Cetacean

\section{INTRODUCTION}

Bryde's whales Balaenoptera edeni are the least known of the large whales (Kato 2002) and are distributed worldwide in tropical and temperate waters, usually between latitudes $40^{\circ} \mathrm{N}$ and $40^{\circ} \mathrm{S}$. They have

\footnotetext{
*Corresponding author: gaby@pachamama.co.nz
}

been widely hunted during the past century and are still exploited in the North Pacific (Kasuya 2002, Baker et al. 2006). The taxonomic status of Bryde's whales remains uncertain. Three species have been proposed: B. edeni, B. brydei and B. omurai (Kato 2002, Wada et al. 2003, Kershaw et al. 2013). The

() The authors 2017. Open Access under Creative Commons by Attribution Licence. Use, distribution and reproduction are unrestricted. Authors and original publication must be credited. 
Society of Marine Mammalogy's Committee on Taxonomy recognizes $B$. omurai but considers the other 2 forms (B. edeni edeni and B. edeni brydei) as subspecies (Committee on Taxonomy 2016). Based on genetic analysis, New Zealand Bryde's whales have been identified as $B$. edeni brydei, the so-called 'offshore form' (Wiseman 2008).

In New Zealand, Bryde's whales are reported only for the north-eastern coast of the North Island (Baker \& Madon 2007, Wiseman 2008) and occur year-round in the Hauraki Gulf (Behrens \& Constantine 2008, Wiseman et al. 2011). The whales have been observed throughout the inner Gulf in water depths ranging from 12 to $60 \mathrm{~m}$ (Wiseman et al. 2011). Some whales have been resighted regularly over multiple years, including reproductive females accompanied by their calves (Wiseman 2008).

In New Zealand, there is currently no information on long-range or seasonal movements along the coast. In the Hauraki Gulf, it appears that there is a higher occurrence of whales during the austral winter (Wiseman et al. 2011), although seasonality was not detected in a more recent study (Dwyer 2014). Bryde's whales in the Hauraki Gulf are subject to a high level of anthropogenic mortality, as evidenced by records of ship strikes and entanglements (Stockin et al. 2008, Wiseman 2008, Riekkola 2013, Constantine et al. 2015). From 1996 to 2014, a total of 44 whales were reported dead. The cause of mortality was determined for 20 carcasses, of which vessel strike was a contributing factor to mortality in $85 \%$ of cases ( $\mathrm{n}=17$ ), while 3 others died as a consequence of entanglement in mussel aquaculture spat lines $(\mathrm{n}=2)$ and unidentified fishing gear $(\mathrm{n}=1$; Constantine et al. 2015). On average, a minimum of 2.3 whales are estimated to be killed by vessel strikes in the Hauraki Gulf every year (Constantine et al. 2015).

The International Union for Conservation of $\mathrm{Na}$ ture (IUCN) classified this species as Data Deficient (Reilly et al. 2008). In New Zealand, Bryde's whales are classified as 'nationally critical' by the New Zealand Threat Classification System because of the apparent small size of the local population in the Hauraki Gulf and the high incidence of ship strikes (Baker et al. 2010, 2016).

Here, we implemented mark-recapture techniques through individual photo-identification using both open models and the robust design. Temporal changes in abundance are considered a function of births, deaths, immigration and emigration. Examining population dynamics is not possible without considering immigration and emigration in the subpopulations.
Pollock's robust design (hereafter referred to as RD; Pollock 1982), allows considerable flexibility in estimating a number of demographic parameters, including apparent survival, abundance and temporary emigration. In addition, POPAN or the 'super population' ( $\hat{N}_{\text {super, }}$ the total number of whales that used the area during the entire course of the study) parameterization of the Jolly-Seber open population model (Crosbie \& Manly 1985, Schwarz \& Arnanson 1996) provides abundance estimates while allowing entries (i.e. birth, immigration) and losses (i.e. death, permanent emigration) in the population under study. This method estimates the abundance of all animals that visited the area during the study period (Williams et al. 2002), providing an estimate of $\hat{N}_{\text {super }}$. This is particularly useful in open populations that are connected to larger metapopulations or where local use is variable over time, as has been hypothesized for Bryde's whales (Wiseman 2008). It appears that a small local population unit of Bryde's whales regularly uses the Hauraki Gulf, although it is considered unlikely that the New Zealand local population would be isolated from a larger (yet unknown) population in the South Pacific (Wiseman 2008).

Monitoring of Bryde's whales in the Hauraki Gulf has primarily been conducted via aerial surveys (Baker \& Madon 2007, Behrens 2009). While this technique provides valuable information on distribution, habitat use and abundance, it does not allow detection of individual changes in site fidelity over time or estimation of population parameters such as apparent survival and temporary emigration. Here, we used photo-identification records collected between 2003 and 2006 and between 2011 and 2013 in the Hauraki Gulf to analyse and compare site fidelity patterns between periods. A subset of this dataset collected during 2004 to 2006 and 2011 to 2013 was further used to estimate local abundance, apparent survival and temporary emigration with the RD and POPAN approaches.

\section{MATERIALS AND METHODS}

\section{Data collection}

From March 2003 to February 2006, sighting and photo-identification records were collected mainly from a commercial whale watch vessel, a $19.9 \mathrm{~m}$ diesel-powered catamaran (hereafter referred to as 'Dolphin Explorer') and several other smaller independent research platforms (Wiseman 2008). Daily surveys typically lasted $5 \mathrm{~h}$ following a non-system- 
atic survey route primarily determined by the prevailing weather conditions (further details in Wiseman et al. 2011).

From August 2011 to December 2013, surveys were conducted in the Hauraki Gulf using 'Dolphin Explorer' and 2 independent research vessels, 'Te Epiwhania' and 'Aihe II'. Both research vessels were $5.5 \mathrm{~m}$ Stabicrafts powered by a 100 and $120 \mathrm{hp} 4$-stroke engine, respectively. Dedicated surveys followed a methodology consistent with Wiseman (2008).

Surveys on 'Dolphin Explorer' were conducted in good visibility $(\geq 1 \mathrm{~km})$, swell $<1 \mathrm{~m}$, and Beaufort sea state $(\mathrm{BSS}) \leq 4$. When onboard the research vessels, surveys were also carried out in good visibility $(\geq 1 \mathrm{~km})$ and swell $<1 \mathrm{~m}$, but in lowered BSS $\leq 3$. The direction of travel was based upon sea state and wind direction, with survey vessel speed maintained at 19 knots for 'Dolphin Explorer' and 11 knots for the research vessels. A survey was discontinued when weather conditions deteriorated (visibility $<1 \mathrm{~km}$, swell $>1 \mathrm{~m}$, BSS $\leq 4$ for the tour boat; BSS $\leq 3$ for the research vessels).

Trip Encounter Rate (TER) was calculated following Wiseman et al. (2011) as the number of trips per month during which whales were observed, expressed as the proportion of the total number of trips undertaken that month. TER provided a monthly index of Bryde's whale occurrence. Only 1 trip d ${ }^{-1}$ was considered in the analyses to avoid pseudoreplication. (Hurlbert 1984). Seasonal analyses were based on austral seasons: spring (September to November), summer (December to February), autumn (March to May) and winter (June to August).

\section{Photo-identification evaluation}

From 2003 to 2006, dorsal fin photographs were collected from Bryde's whales in the Hauraki Gulf using Cannon 20D and EOS5 cameras fitted with a Tamron 200 to $400 \mathrm{~mm}$ lens. During 2011 to 2013, dorsal fin photographs were collected using a Nikon D7000 fitted with a Tamron 200 to $400 \mathrm{~mm}$ lens. Attempts were made to photograph both sides of the dorsal fin.

The photographic quality of the images and the distinctiveness of nicks used for individual identification were evaluated using a quality scale (see Table S1 in the Supplement at www.int-res.com/ articles/suppl/n034p061_supp.pdf). Each image was classified into 5 categories of photo quality (excellent, good, fair, average or poor) according to focus, exposure (contrast between dorsal fin and back- ground), size of the dorsal fin relative to the frame (definition) and relative angle of the camera to the whale (Blackmer et al. 2000, Friday et al. 2000, Stevick et al. 2001). Photographs of each individual were graded according to a scale of nick distinctiveness, ranging from 1 (very distinctive dorsal fin) to 5 (nondistinctive dorsal fin; see Table S2 in the Supplement). Images were matched to the catalogue, and when a match was found, records were updated accordingly. New individuals were cross-matched by 2 experienced researchers, given a new access number and added to the catalogue.

Overall, 28 whales (and their associated sighting data) were excluded from these analyses. Deleted data were included in a former study conducted by Wiseman (2008). Of these, 8 presented poor quality images and 20 were classified as having a nondistinctive dorsal fin. Wiseman (2008) included 'fin shape' and scars as attributes to identify whales. While fin shape and scarring may be used as secondary features to assist with the identification of whales (Penry 2010), they cannot be considered sufficient to identify individuals over time. This is because fin shape can be easily distorted by the angle at which the image has been taken, as observed in whale carcasses examined post-mortem (K. A. Stockin unpubl. data). In addition, the stability of scarring is unknown for this species. As such, we deemed identification of whales based solely on fin shape and/or scarring to be unreliable, especially for a long-term study that includes comparisons over an 8 yr period.

\section{Site fidelity}

Site fidelity of Bryde's whales in the Hauraki Gulf was examined using photo-identification sighting records collected between 2003 and 2006, and between 2011 and 2013. Monthly (MSR) and seasonal sighting rates (SSR) were calculated by expressing the number of months a whale was identified as a proportion of the total number of months in which at least 1 survey was conducted and the number of seasons in which a whale was identified as a proportion of the total seasons surveyed (Parra et al. 2006, Cagnazzi et al. 2011). MSR could therefore range between 0.015 for a whale sighted in only 1 survey month, to 1 for an individual observed in all 65 survey months. Similarly, SSR could range between 0.04 for a whale sighted in only 1 season out of 23 , to 1 for an individual recorded in all 23 seasons across the study. 


\section{Mark ratio}

As with other cetacean populations, not all whales exhibited sufficient marks for individual recognition. To account for these unmarked individuals, we estimated a mark ratio (Jolly 1965). High quality photographs (only photos categorized 'excellent' and 'good quality') from each encounter were counted to estimate the proportion of whales with distinctive marks (mark ratio). Total abundance was estimated as follows:

$$
\hat{N}_{\text {total }}=\hat{N}_{\mathrm{m}} / \hat{P}_{\mathrm{m}}
$$

where $\hat{N}_{\mathrm{m}}$ is the abundance of marked whales and $\hat{P}_{\mathrm{m}}$ is the proportion of marked whales. The variance was estimated using the delta method (Wilson et al. 1999) as follows:

$$
\operatorname{var}\left(\hat{N}_{\text {total }}\right)=\hat{N}_{\text {total }}^{2}\left[\frac{\operatorname{Var}\left(\hat{N}_{\mathrm{m}}\right)}{\hat{N}_{\mathrm{m}}^{2}}+\frac{1-\hat{P}_{\mathrm{m}}}{n \hat{P}_{\mathrm{m}}}\right]
$$

where $n$ is the total number of occasions from which $\hat{P}_{\mathrm{m}}$ was estimated. The standard error was calculated as follows:

$$
\operatorname{SE}\left(\hat{N}_{\text {total }}\right)=\sqrt{\operatorname{var}\left(\hat{N}_{\text {total }}\right)}
$$

Log-normal confidence intervals for each estimate of abundance were calculated (Burnham et al. 1987) as follows:

$$
\hat{N}_{\text {lower }}=\frac{\hat{N}_{\text {total }}}{C}
$$

and

$$
\hat{N}_{\text {upper }}=\hat{N}_{\text {total }} \times C
$$

where

$$
C=\exp \left(z_{\alpha / 2} \sqrt{\log _{\mathrm{e}}\left\{1+\left[\mathrm{CV}\left(\hat{N}_{\text {total }}\right)\right]^{2}\right\}}\right)
$$

where $\hat{N}_{\text {lower }}$ is the lower bound of the confidence interval, $\hat{N}_{\text {upper }}$ is the upper bound of the confidence interval, $Z_{\alpha / 2}$ is the normal deviate, $\alpha=0.05$ and $C V$ is the coefficient of variation.

\section{Goodness of fit}

To conduct goodness of fit tests, data were pooled into seasons (rather than months) to avoid sparseness due to low data density (Cooch \& White 2011) and analysed in a Cormack-Jolly-Seber (CJS) framework.
This approach provides a goodness of fit test for primary sessions for the RD and seasons for POPAN. The variance inflation factor $(\hat{\mathrm{c}})$ was estimated using a median $\hat{\mathrm{c}}$ approach as implemented in MARK (Cooch \& White 2011). To evaluate potential violations of mark-recapture assumptions, goodness of fit tests (test 2 [2.CT and 2.CL] and test 3 [3.SR and 3.SL]) were run in U-CARE v.2.2 (Choquet et al. 2005) following Tezanos-Pinto et al. (2013).

The RD does not have a specific goodness of fit test. However, data can be evaluated using current open and closed models accordingly. U-CARE was implemented using a CJS framework across primary periods (i.e. seasons) to examine potential violations of assumptions (tests 2 and 3). In addition, CloseTest (Stanley \& Burnham 1999) was implemented to examine if data from each secondary period fulfilled the closure assumption.

\section{Mark-recapture dataset}

During 2003, there were relatively few photoidentification surveys conducted in the Hauraki Gulf because of a reduced tour schedule for 'Dolphin Explorer'. To minimize heterogeneity (i.e. over-dispersion), data collected during 2003 were excluded from mark-recapture analyses. Photo-identification data collected from 2004 to 2006 and 2011 to 2013 were pooled by austral seasons to estimate apparent survival, abundance and the total number of whales that used the area during the course of the study (i.e. $\hat{N}_{\text {super }}$. Monthly and annual periods were considered but not deemed suitable as pooling these resulted in either over- or under-dispersion. Periods were analysed separately to estimate abundance and account for potential differences in the area covered between periods (mostly inner Hauraki Gulf between 2004 and 2006; inner and outer Hauraki Gulf including Great Barrier Island from 2011 to 2013). However, data were combined to estimate apparent survival since it was of interest to examine whale survival across periods.

\section{Population abundance models}

RD structure

Mark-recapture data were extracted from the complete photo-identification dataset to fit a sampling structure of closely adjacent secondary samples (i.e. daily surveys: 1 survey $\mathrm{d}^{-1}$ ) within more widely sepa- 
rated primary samples (i.e. seasons). Following this structure, data were stratified by austral seasons to estimate the number of whales present in the Hauraki Gulf, rates of temporary emigration and apparent survival. For each season, we estimated the capture probability $(p)$ and abundance $\left(\hat{N}_{\mathrm{m}}\right)$ of whales in the Hauraki Gulf. From the intervals between seasons, we estimated apparent survival (Ø) and temporary emigration $\left(\gamma^{\prime}\right.$ and $\left.\gamma^{\prime \prime}\right)$. Capture probability was modelled to vary between seasons $(s=$ seasons or primary samples) and within seasons ( $t=$ daily surveys within a season or secondary samples). Recapture probabilities were constrained to equal capture probabilities on each occasion for all models, because there was no evidence of a behavioural effect on capture. Temporary emigration was modelled assuming no emigration (i.e. $\gamma^{\prime \prime}=\gamma^{\prime}=0$ ), random (i.e. $\gamma^{\prime \prime}=\gamma^{\prime}$ ), Markovian temporary emigration (i.e. $\gamma^{\prime \prime} \neq \gamma^{\prime}$ ) and the even flow model $\left(\gamma^{\prime \prime}=1-\gamma^{\prime}\right.$; Huggins 1991, Kendall et al. 1997).

\section{POPAN design structure}

The Schwarz and Arnason 'super population' parameterization of the Jolly-Seber model (i.e. POPAN; Crosbie \& Manly 1985, Schwarz \& Arnanson 1996) was applied to estimate apparent survival and abundance of whales in the Hauraki Gulf (Williams et al. 2002) during the study period. In addition, this approach allows estimating the probability of entry ( $\beta$ ). Models incorporated a seasonal structure in the design matrix to evaluate whether seasonality explained capture probabilities and apparent survival. TER was added into the design matrix to examine if capture probabilities were explained by effort. In order to estimate all parameters in the fully parameterized model, a constraint was added to the first and last capture probabilities (i.e. $p_{1}=p_{2}$ and $p_{k}=p_{k-1}$; Cooch \& White 2011). POPAN provides an estimate of $\hat{N}_{\text {super }}$.

\section{Potential biological removal}

Any marine mammal population with an estimate of human-induced mortality that is greater than its potential biological removal (PBR) has a level of mortality that could lead to the depletion of the population (Wade 1998). We conducted a PBR analysis following Wade (1998):

$$
\mathrm{PBR}=N_{\mathrm{MIN}} \frac{1}{2} R_{\mathrm{MAX}} F_{\mathrm{R}}
$$

where $N_{\text {MIN }}$ is $20^{\text {th }}$ percentile log-normal total abundance estimate of the stock, $R_{\mathrm{MAX}}$ is one-half the maximum theoretical or estimated net productivity rate of the stock at a small population size, and $F_{\mathrm{R}}=\mathrm{a}$ recovery factor between 0.1 and 1 .

\section{RESULTS}

\section{Effort}

Between January 2004 and February 2006, a total of 261 daily surveys were conducted in the Hauraki Gulf (Fig. 1). Average seasonal TER ranged from a low of 0.33 during spring to a high of 0.51 during summer and winter $(\bar{x}=0.46$; Table 1$)$ and did not differ significantly among seasons (Kruskal-Wallis test, $H_{3}=10.4, \mathrm{p}=0.693$ ) or across years (Kruskal-Wallis test, $H_{3}=4.99, \mathrm{p}=0.08$ ).

Data collected during August 2011 to December 2013 included 382 daily surveys (Fig. 1). Average seasonal TER ranged from a low of 0.44 in autumn to a high of 0.81 in spring $(\bar{x}=0.57)$ and did not differ significantly among seasons (Kruskal-Wallis test, $\mathrm{H}_{3}=$ $5.43, \mathrm{p}=0.70$ ) or across years (Kruskal-Wallis test, $H_{2}=1.50, \mathrm{p}=0.47$ ). However, there were significant differences when comparing average monthly TER

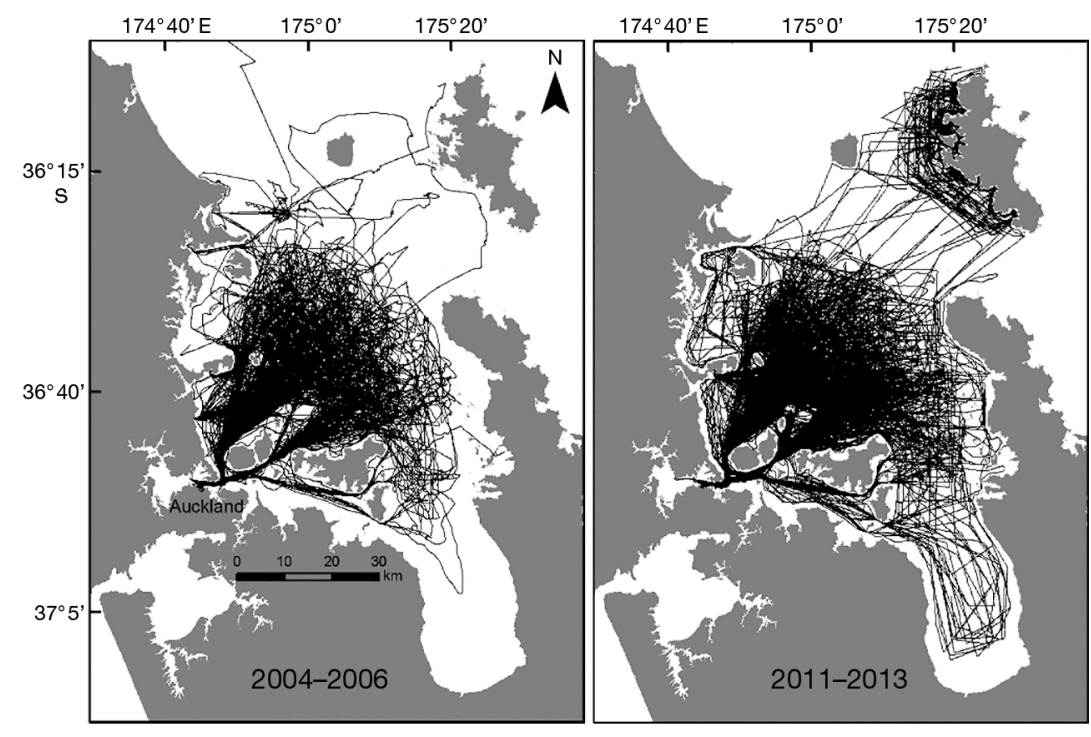

Fig. 1. Hauraki Gulf, including track effort (black lines) obtained while conducting surveys between 2004 and $2006(\mathrm{n}=261)$, and between 2011 and $2013(n=382)$ 
Table 1. Total number of daily surveys, total number of observations of Bryde's whales, and trip encounter rate (TER) in the Hauraki Gulf between 2004 and 2006, and 2011 and 2013, with average for each season listed below monthly values

\begin{tabular}{|c|c|c|c|c|c|c|c|}
\hline \multirow[t]{2}{*}{ Season } & \multirow[t]{2}{*}{ Month } & \multicolumn{3}{|c|}{$2004-2006$} & \multicolumn{3}{|c|}{$-2011-2013$} \\
\hline & & $\begin{array}{c}\text { Daily } \\
\text { surveys }\end{array}$ & $\begin{array}{l}\text { No. obs. } \\
\text { whales }\end{array}$ & TER & $\begin{array}{c}\text { Daily } \\
\text { surveys }\end{array}$ & $\begin{array}{c}\text { No. obs. } \\
\text { whales }\end{array}$ & TER \\
\hline \multirow[t]{3}{*}{ Summer } & December & 16 & 19 & 0.51 & 44 & 29 & 0.66 \\
\hline & January & 37 & 16 & 0.64 & 24 & 7 & 0.29 \\
\hline & February & 25 & 13 & 0.52 & 30 & 10 & 0.33 \\
\hline Summer average & & & & 0.51 & & & 0.47 \\
\hline \multirow[t]{3}{*}{ Autumn } & March & 25 & 7 & 0.28 & 30 & 8 & 0.27 \\
\hline & April & 25 & 10 & 0.42 & 30 & 17 & 0.57 \\
\hline & May & 24 & 12 & 0.41 & 21 & 8 & 0.38 \\
\hline Autumn average & & & & 0.42 & & & 0.41 \\
\hline \multirow[t]{3}{*}{ Winter } & June & 29 & 13 & 0.54 & 29 & 12 & 0.41 \\
\hline & July & 24 & 10 & 0.71 & 33 & 20 & 0.61 \\
\hline & August & 14 & 3 & 0.27 & 40 & 27 & 0.68 \\
\hline Winter average & & & & 0.51 & & & 0.58 \\
\hline \multirow[t]{3}{*}{ Spring } & September & 11 & 6 & 0.40 & 27 & 22 & 0.81 \\
\hline & October & 15 & 5 & 0.31 & 35 & 30 & 0.86 \\
\hline & November & 16 & 5 & 0.31 & 39 & 32 & 0.82 \\
\hline Spring average & & & & 0.33 & & & 0.84 \\
\hline Total & & 261 & 119 & Mean: 0.46 & 382 & 222 & Mean: 0.58 \\
\hline
\end{tabular}

values per year between periods (2004 to 2006 and 2011 to 2013; Mann-Whitney test, $U_{1}=5.88, \mathrm{p}=0.01$ ).

\section{Photo-identification}

The original photo-identification catalogue from Wiseman (2008) contained 72 unique whales. After the removal of 28 whales and their associated sighting data (see 'Materials and methods'), the catalogue contained 44 unique whales. New photo-identification data collected between 2011 and 2013 resulted in a total of 48 unique whales, of which 28 represented new individuals and 20 were resightings of previously catalogued whales. Overall, the final catalogue contained 352 sighting records of 72 unique whales from 2003 to 2006 and 2011 to 2013. During 2003, there were only 26 sighting records representing 11 unique whales ( 2 whales were only sighted during 2003); this information was used for site fidelity analyses but excluded from mark-recapture estimates to avoid introducing heterogeneity.

\section{Site fidelity}

The majority of whales $(n=43)$ were sighted during $\leq 3$ months across the 65 surveyed months, 24 whales were sighted during 4 to 10 survey months, and 5 were sighted during 11 to 15 survey months (Fig. 2). Overall, MSR ranged from a low of $1.5 \%$ (whales sighted during only one month) to a high of $23.1 \%$ (whales sighted 15 out of 65 months), with an overall mean $( \pm \mathrm{SE})$ of $5.6 \pm 0.6 \%$. Similarly, the majority of whales $(\mathrm{n}=$ $50)$ were sighted during $\leq 3$ of the 23 seasons, 20 whales were sighted in 4 to 9 seasons and 2 whales were sighted across 10 and 13 seasons, respectively. Accordingly, SSR ranged from a low of $4.2 \%$ (for a whale sighted in only 1 season) to a high of $56.5 \%$ (for a whale sighted in 13 of 23 seasons), with an overall mean of $12.4 \pm 1.2 \%$ (Fig. 2).

Of the 72 unique whales evaluated, 20 were sighted across the 2 periods (2003 to 2006 and 2011 to 2013); however, MSR varied among whales between periods (Fig. 3). For example, whale ID12 (female; Wiseman 2008) was sighted across 11 months $(\mathrm{MSR}=16.9 \%)$ during 2003 to 2006 but never sighted during 2011 to 2013. Whales ID22 and ID23 (both females) were sighted across 8 and 9 months during 2003 to 2006, respectively. However, during 2011 to 2013 they were observed only during 5 and 2 months, respectively. Whale ID90 (female) was sighted 10 out of 29 months (MSR = 34.5\%; Fig. 3) only during 2011 to 2013. These results suggest that some whales changed their site fidelity patterns over time. 


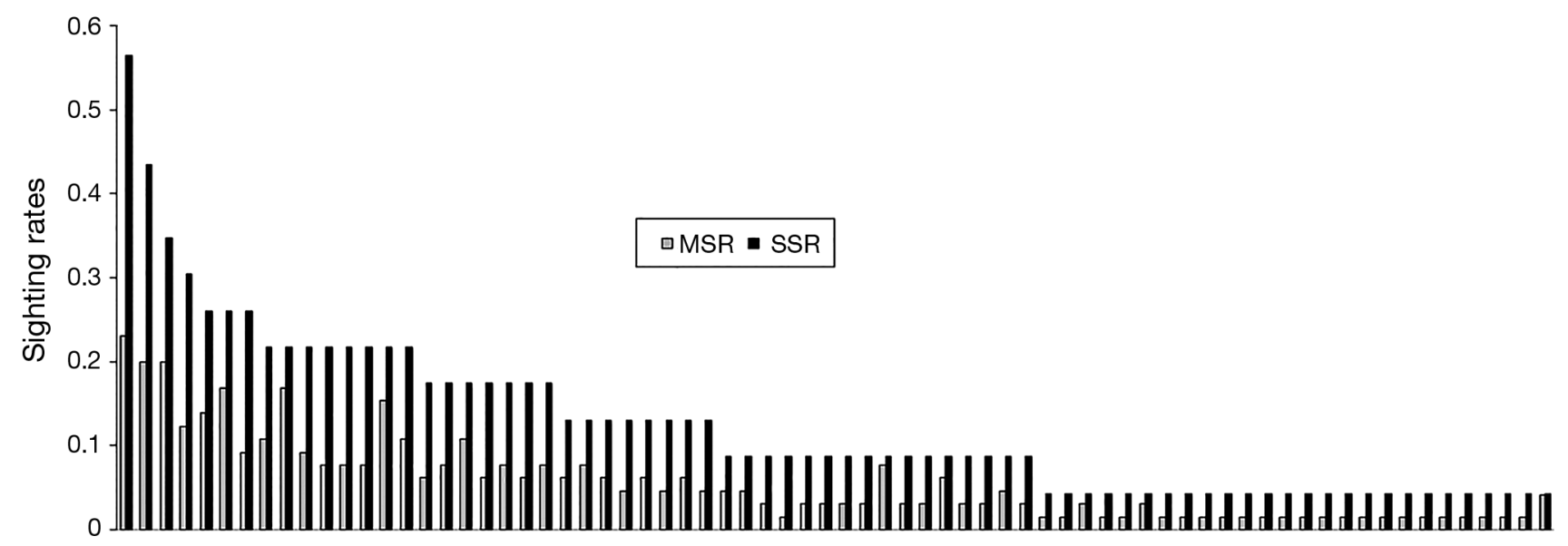

Fig. 2. Monthly (MSR; grey) and seasonal sighting rates (SSR; black) for individual Bryde's whales photo-identified in the Hauraki Gulf from 2003 to 2006 and 2011 to 2013

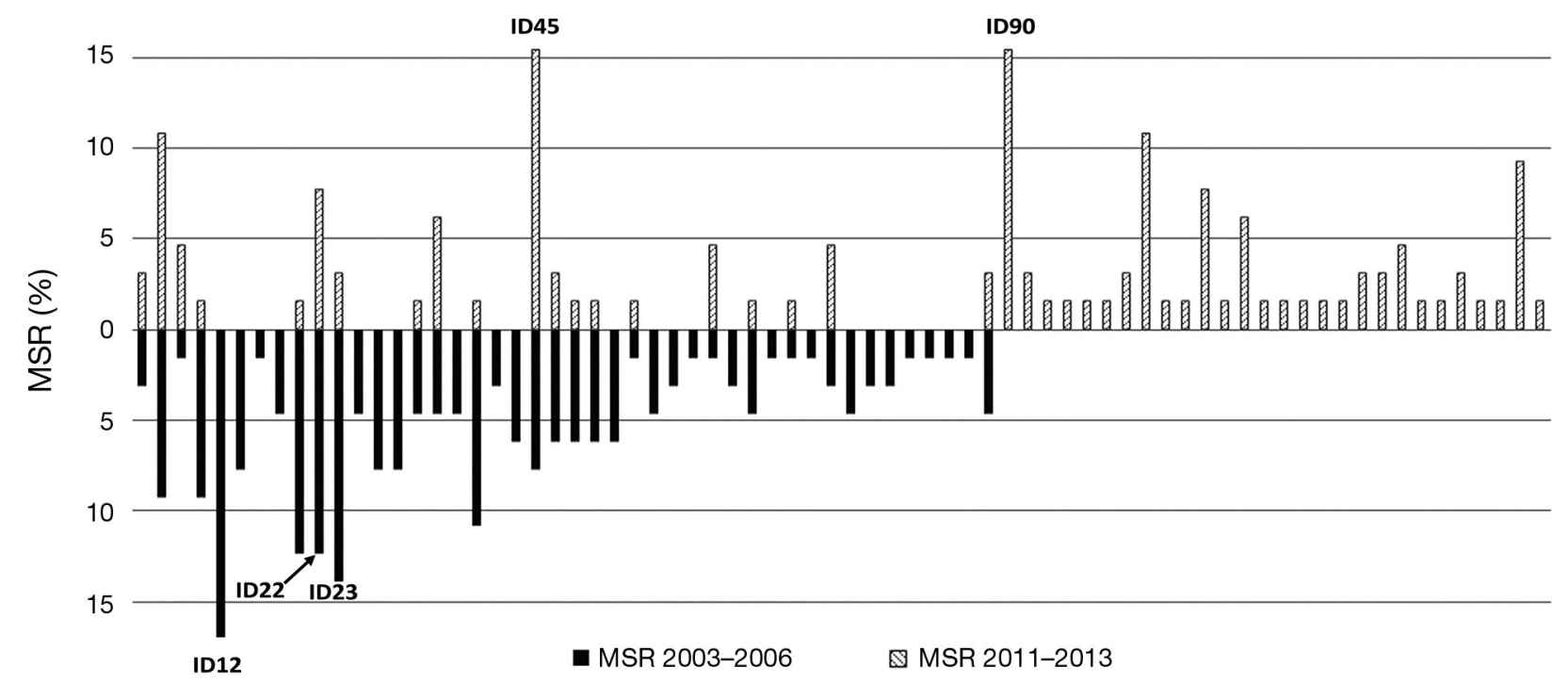

Fig. 3. Monthly seasonal sighting rates (MSR, in percentage) for individual Bryde's whales (each vertical line represents a whale) photo-identified in the Hauraki Gulf from 2003 to 2006 (black) and 2011 to 2013 (hatched). Whales ID12, 22, 23, 45 and 90 are labelled (see 'Site fidelity')

\section{Mark ratio}

The mark ratio for 2004 to 2006 was re-estimated excluding individuals that did not meet photo-quality and/or nick distinctiveness criteria. A total of 131 sightings of whales were used, of which 83 were uniquely marked individuals, resulting in a ratio of 0.633 ( $\mathrm{SE}=0.06)$. Using the same criteria, the mark ratio for 2011 to 2013 was estimated over 181 sightings, of which 91 were 'marked' whales, resulting in a ratio of $0.497(\mathrm{SE}=0.04)$. All abundance estimates presented here were scaled up to their corresponding mark ratio (i.e. $63.3 \%$ for 2004 to 2006 and
$49.7 \%$ for 2011 to 2013). Despite the difference, the mark ratio between periods did not vary significantly $(F=0.253)$.

\section{Goodness of fit}

For the 2004 to 2006 dataset, the estimated $\hat{c}$ was indicative of no over-dispersion ( $\hat{\mathrm{c}}=0.987$ ), and was set to 1 as recommended by Cooch \& White (2011). Results for the global test in U-CARE were not significant (test $2+$ test $3, \chi^{2}=16.843, p=0.470, \mathrm{df}=17$ ). Correspondingly, none of the tests showed signifi- 
cant departure from assumptions (test 2.CT, p = 0.143 ; test $2 . \mathrm{CL}, \mathrm{p}=0.597$; test $3 . \mathrm{SM}, \mathrm{p}=0.993$; test 3.SR, $\mathrm{p}=0.768$ ).

For the 2011 to 2013 dataset, the estimated $\hat{\mathrm{C}}$ was indicative of under-dispersion $(\hat{\mathrm{c}}=0.535)$, and was set to 1 as recommended by Cooch \& White (2011). Results for the global test in U-CARE were not significant (test $2+$ test $3, \chi^{2}=9.627, \mathrm{p}=0.920$, $\mathrm{df}=18$ ). Correspondingly, none of the tests showed significant departure from assumptions (test 2.CT, p = 0.914 ; test 2.CL, $\mathrm{p}=0.597$; test $3 . \mathrm{SM}, \mathrm{p}=0.709$; test 3.SR, $\mathrm{p}=0.829$ ).

\section{Population abundance models}

Robust design

The 2004 to 2006 dataset included 9 primary periods (seasons) composed of 106 secondary sessions (i.e. days; Table 2). Annual time intervals ranged from 0.234 to 0.277 . The best fitting RD model (based on corrected Akaike's information criterion [AICc] score) suggested a population with constant apparent survival, capture probabilities and temporary emigration (Table 3). Abundance estimates correcting for the proportion of unmarked whales between 2004 and 2006 ranged from a low of $17(95 \% \mathrm{CI}=10-28 ; \mathrm{CV}=$ $0.26)$ to a high of 43 whales $(95 \% \mathrm{CI}=25-73$; $\mathrm{CV}=$ 0.28; Fig. 4). Temporary emigration was estimated at
0.557 (95\% CI = 0.439-0.669) and capture probability at $0.081(95 \% \mathrm{CI}=0.070-0.094)$.

The 2011 to 2013 dataset included 8 primary periods (seasons) composed of 102 secondary sessions (i.e. days; Table 2). Annual time intervals ranged from 0.184 to 0.488 . The best fitting RD model (based on AICc score) suggested a population with constant apparent survival, capture probability and temporary emigration (Table 3). However, a second model with constant apparent survival, temporary emigration and seasonal capture probabilities presented a high AICc weight (0.412). Consequently, model averaging was implemented to estimate all parameters (Cooch \& White 2011).

Abundance estimates correcting for the proportion of unmarked whales during 2011 to 2013 ranged from a low of $13(95 \% \mathrm{CI}=9-18, \mathrm{CV}=0.17)$ to a high of 32 whales $(95 \% \mathrm{CI}=16-61, \mathrm{CV}=0.11$; Fig. 4). Temporary emigration was estimated at 0.610 (95\% $\mathrm{CI}=0.454-0.747$ ) and capture probability at 0.105 $(95 \% \mathrm{CI}=0.068-0.160)$.

\section{POPAN analyses}

Several models were evaluated, including those that incorporated effort (i.e. TER) in the design matrix, as well as variations in the parameters by time and season; however, only the 6 best fitting models are presented (Table 3).

Table 2. Structure of the robust design (RD) for Bryde's whale data collected in the Hauraki Gulf from 2004 to 2006 and 2011 to 2013, including primary sessions (seasons) and secondary periods (days), start and end of each session, duration, total number of unique whales identified within each session, annual intervals between sessions, number of secondary sessions within each primary session and results from CloseTest (Stanley and Burnham closure test)

\begin{tabular}{|c|c|c|c|c|c|c|c|c|}
\hline $\begin{array}{l}\text { Primary } \\
\text { session }\end{array}$ & Year & Season & Start session & End session & $\begin{array}{c}\text { Unique } \\
\text { whales ID }\end{array}$ & $\begin{array}{c}\text { Annual } \\
\text { intervals }\end{array}$ & $\begin{array}{c}\text { Secondary } \\
\text { sessions }\end{array}$ & $\begin{array}{c}\text { Close } \\
\text { test }\end{array}$ \\
\hline 1 & 2003-2004 & Summer & 04-Jan-04 & 09-Mar-04 & 7 & & 5 & 0.398 \\
\hline 2 & 2004 & Autumn & 23-Mar-04 & 13-Jun-04 & 11 & 0.240 & 9 & 0.362 \\
\hline 3 & 2004 & Winter & 26-Jun-04 & 07-Sep-04 & 9 & 0.248 & 5 & 0.998 \\
\hline 4 & 2004 & Spring & 22 -Oct-04 & 30-Nov-04 & 8 & 0.277 & 6 & 0.474 \\
\hline 5 & 2004-2005 & Summer & 03-Jan-05 & 13-Mar-05 & 27 & 0.241 & 16 & 0.312 \\
\hline 6 & 2005 & Autumn & 26-Mar-05 & 16-Jun-05 & 38 & 0.242 & 23 & 0.722 \\
\hline 7 & 2005 & Winter & 01-Jul-05 & 14-Sep-05 & 31 & 0.256 & 22 & 0.790 \\
\hline 8 & 2005 & Spring & 13-Oct-05 & 02-Dec-05 & 12 & 0.251 & 6 & 0.597 \\
\hline 9 & 2005-2006 & Summer & 07-Jan-06 & $25-F e b-06$ & 16 & 0.234 & 14 & 0.586 \\
\hline 1 & 2011 & Winter & 20-Aug-11 & 09-Sep-11 & 12 & & 9 & 0.853 \\
\hline 2 & 2011 & Spring & 22-Sep-11 & 19-Dec-11 & 19 & 0.184 & 13 & 0.286 \\
\hline 3 & 2012 & Autumn & 28-Mar-12 & 04-Jun-12 & 17 & 0.488 & 15 & 0.205 \\
\hline 4 & 2012 & Winter & 30-Jun-12 & 19-Sep-12 & 22 & 0.275 & 14 & 0.115 \\
\hline 5 & 2012 & Spring & $09-$ Oct-12 & 15-Dec-12 & 21 & 0.258 & 10 & 0.060 \\
\hline 6 & $2012-2013$ & Summer & 10-Jan-13 & 07-Mar-13 & 15 & 0.240 & 11 & 0.156 \\
\hline 7 & 2013 & Winter & 09-Jul-13 & 28-Aug-13 & 9 & 0.485 & 9 & 0.236 \\
\hline 8 & 2013 & Spring & $02-$-Oct-13 & 11-Dec-13 & 49 & 0.260 & 21 & 0.171 \\
\hline
\end{tabular}


Table 3. Model selection for mark-recapture data of Bryde's whales in the Hauraki Gulf. Models displayed include the first 6 best models for the robust design (RD, top) and seasonal POPAN data (bottom) for each period. $\varnothing$ : apparent survival; $p$ : capture; $c$ : recapture; $\gamma^{\prime}$ and $\gamma^{\prime \prime}$ : temporary emigration probabilities; $\beta$ : probability of entry; TER: trip encounter rate (see 'Materials and methods: Data collection'). For the RD: $s$ : seasons or primary samples; $t$ : daily surveys within a season. The lowest corrected Akaike's information criterion (AICc) value represents the model that has the most support from the data. NP: number of parameters. Notation: $\gamma^{\prime}=\gamma^{\prime \prime}=0$ : no temporary emigration; $\gamma=\gamma^{\prime \prime}(\mathrm{x})=\gamma^{\prime}(\mathrm{x})$ : random temporary emigration; $\gamma^{\prime \prime}(\mathrm{x}) \neq \gamma^{\prime}(\mathrm{x})$ : Markovian temporary emigration; constant parameter $p=c(\mathrm{x})=$ no behavioural effect on capture (following Kendall et al. 1997). ML: model likelihood; QDev: deviance. RD models that incorporated TER in the design matrix scored after model 6 and are not shown here

\begin{tabular}{|c|c|c|c|c|c|c|c|}
\hline \multicolumn{2}{|c|}{ Models } & $\mathrm{AICc}$ & $\triangle \mathrm{AICC}$ & AICc weights & ML & NP & QDev \\
\hline \multicolumn{8}{|c|}{ Robust design } \\
\hline \multicolumn{8}{|c|}{ Dataset 2004-2006 } \\
\hline 1 & $\varnothing(.) \gamma() p=.c()$. & 839.177 & 0 & 0.81505 & 1 & 12 & 785.293 \\
\hline 2 & $\varnothing(.) \gamma() p=.c(s)$ & 843.481 & 4.303 & 0.09479 & 0.1163 & 15 & 782.321 \\
\hline 3 & $\varnothing(.) \gamma^{\prime \prime}(.) \neq \gamma^{\prime}() p=.C()$. & 843.606 & 4.428 & 0.08904 & 0.1092 & 16 & 779.950 \\
\hline 4 & $\varnothing(.) \gamma() p=.c(t)$ & 854.042 & 14.865 & 0.00048 & 0.0006 & 20 & 780.022 \\
\hline 5 & $\varnothing(.) \gamma^{\prime \prime}(.) \neq \gamma^{\prime}() p=.c()$. & 854.594 & 15.417 & 0.00037 & 0.0005 & 21 & 777.885 \\
\hline 6 & $\varnothing(.) \gamma^{\prime \prime}(t) \neq \gamma^{\prime}(t) p=c(t)$ & 855.198 & 16.021 & 0.00027 & 0.0003 & 29 & 755.396 \\
\hline \multicolumn{8}{|c|}{ Dataset 2011-2013 } \\
\hline 1 & $\varnothing(.) \gamma() p=.c()$. & 805.654 & 0 & 0.54525 & 1 & 11 & 717.000 \\
\hline 2 & $\varnothing(.) \gamma() p=.c(s)$ & 806.215 & 0.561 & 0.41189 & 0.755 & 13 & 712.791 \\
\hline 3 & $\varnothing(.) \gamma^{\prime \prime}(.) \neq \gamma^{\prime}() p=.C()$. & 810.767 & 5.113 & 0.0423 & 0.078 & 19 & 702.148 \\
\hline 4 & $\varnothing(t) \gamma^{\prime \prime}(.) \neq \gamma^{\prime}() p=.C()$. & 819.435 & 13.780 & 0.00055 & 0.001 & 23 & 699.875 \\
\hline 5 & $\varnothing(.) \gamma^{\prime \prime}(t) \neq \gamma^{\prime}(t) p=c()$. & 827.242 & 21.588 & 0.00001 & 0 & 30 & 686.752 \\
\hline 6 & $\varnothing(t) \gamma^{\prime \prime}(t) \neq \gamma^{\prime}(t) p=c(t)$ & 846.908 & 41.253 & 0 & 0 & 36 & 686.395 \\
\hline \multicolumn{8}{|c|}{ POPAN } \\
\hline \multicolumn{8}{|c|}{ Dataset 2004-2006 } \\
\hline 1 & $\varnothing() p.(.) \beta()$. & 276.394 & 0 & 0.84818 & 1 & 4 & 37.184 \\
\hline 2 & $\varnothing() p.(s) \beta()$. & 280.162 & 3.768 & 0.12891 & 0.152 & 7 & 40.024 \\
\hline 3 & $\varnothing() p.(t) \beta()$. & 284.544 & 8.15 & 0.01441 & 0.017 & 12 & 48.313 \\
\hline 4 & $\varnothing() p.(.) \beta(t)$ & 285.916 & 9.522 & 0.00726 & 0.0086 & 11 & 44.333 \\
\hline 5 & $\varnothing(t) p(.) \beta()$. & 289.445 & 13.051 & 0.00124 & 0 & 11 & 40.804 \\
\hline 6 & $\varnothing() p.($ TER) $\beta()$. & 295.640 & 19.246 & 0 & 0 & 12 & 37.217 \\
\hline \multicolumn{8}{|c|}{ Dataset 2011-2013 } \\
\hline 1 & $\varnothing() p.(s) \beta()$. & 236.671 & 0 & 0.7662 & 1 & 7 & 48.365 \\
\hline 2 & $\varnothing() p.(.) \beta()$. & 239.987 & 3.316 & 0.1460 & 0.190 & 4 & 38.041 \\
\hline 3 & $\varnothing() p.(t) \beta()$. & 241.009 & 4.337 & 0.0876 & 0.114 & 12 & 57.081 \\
\hline 4 & $\varnothing(t) p(.) \beta()$. & 254.319 & 17.645 & 0.0001 & 0.0001 & 11 & 41.001 \\
\hline 5 & $\varnothing() p.($ TER) $\beta()$. & 258.891 & 22.219 & 0 & 0 & 12 & 39.199 \\
\hline 6 & $\varnothing(t) p(t) \beta()$. & 259.975 & 23.304 & 0 & 0 & 19 & 59.985 \\
\hline
\end{tabular}

For the 2004 to 2006 dataset, the model that best explained the data consisted of all constant parameters (Model 1). Parameter estimates from this model resulted in probability of entry $=0.073(95 \% \mathrm{CI}=$ $0.044-0.118)$ and capture probability $=0.288(95 \%$ $\mathrm{CI}=0.202-0.392$ ). Seasonal abundance correcting for the proportion of unmarked animals during 2004 to 2006 ranged from $38(95 \% \mathrm{CI}=20-73 ; \mathrm{CV}=0.34)$ to 75 whales $(95 \% \mathrm{CI}=50-111 ; \mathrm{CV}=0.20)$. The abundance of all the whales that visited the area during this period was estimated at $94(95 \% \mathrm{CI}=$ $74-120 ; \mathrm{CV}=0.12$ ).

For the 2011 to 2013 dataset, the model that best explained the data consisted of constant survival and probability of entry and seasonal capture probabili- ties. Parameters estimated from this model resulted in probability of entry $=0.043(95 \% \mathrm{CI}=0.020-0.087)$. Seasonal capture probabilities ranged from 0.161 during summer $(95 \% \mathrm{CI}=0.084-0.289), 0.203$ during autumn $(95 \% \mathrm{CI}=0.070-0.461), 0.278$ during spring $(95 \% \mathrm{CI}=0.153-0.451)$ and 0.282 during winter $(95 \% \mathrm{CI}=0.1723-0.426)$. Abundance correcting for the proportion of unmarked animals ranged from 42 $(95 \% \mathrm{CI}=27-64 ; \mathrm{CV}=0.22)$ to 68 whales $(95 \% \mathrm{CI}=$ $43-106 ; \mathrm{CV}=0.23$; Fig. 5). The abundance of all the whales that visited the area during this period was estimated at $135(95 \% \mathrm{CI}=100-183 ; \mathrm{CV}=0.16)$.

Apparent survival combining both datasets (2004 to 2006 and 2011 to 2013) was estimated at 0.878 $(95 \% \mathrm{CI}=0.811-0.923)$. 


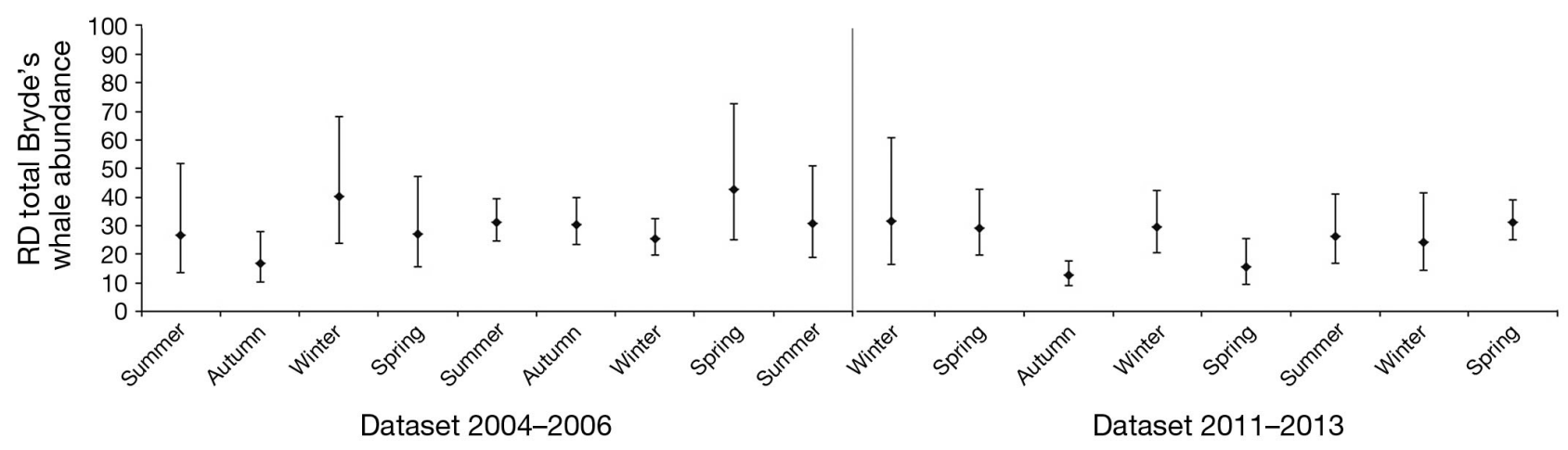

Fig. 4. Seasonal abundance estimates of Bryde's whales in the Hauraki Gulf from 2004 to 2006, and 2011 to 2013 (marked and unmarked animals) obtained using the robust design (RD), including $95 \%$ confidence intervals (vertical bars)

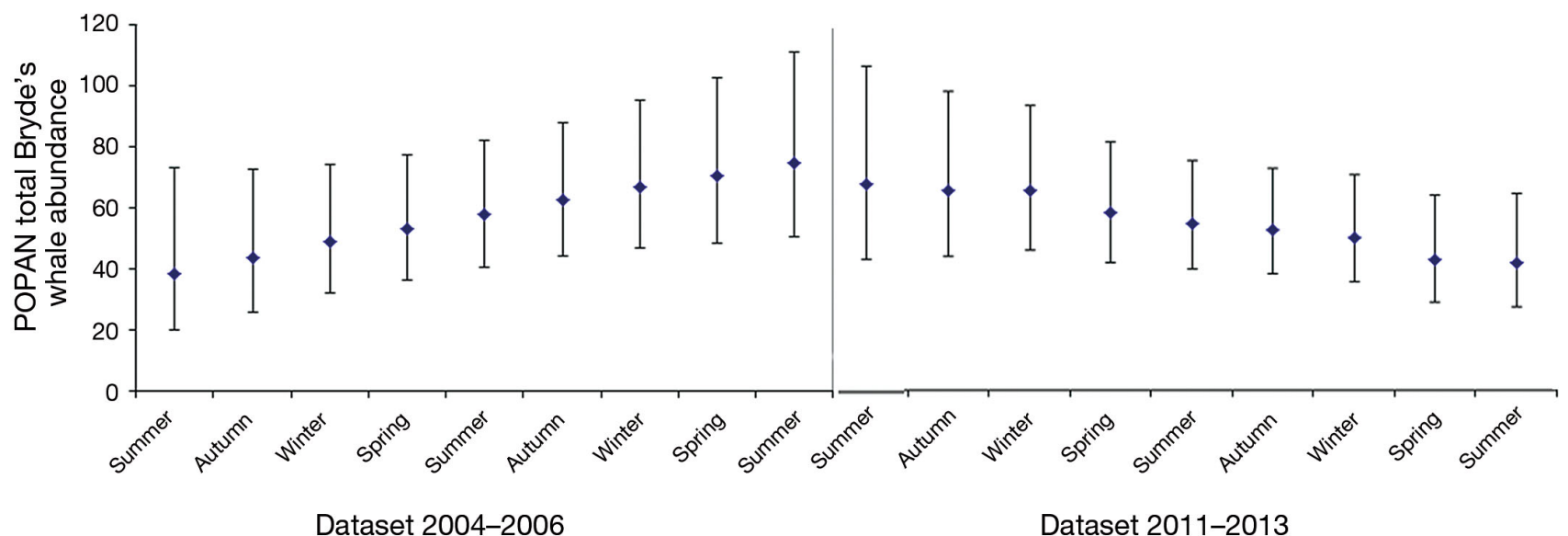

Fig. 5. Seasonal abundance estimates of Bryde's whales (marked and unmarked animals) in the Hauraki Gulf from 2004 to 2006 and 2011 to 2013 obtained using POPAN, including $95 \%$ confidence intervals (vertical bars)

PBR

Following Wade (1998), we set the recovery factor at 0.5 and the maximum rate of increase at 0.04 . Abundance estimates for $\hat{N}_{\text {super }}$. during 2011 to 2013 and its corresponding $\mathrm{CV}$ were used $\left(\hat{\hat{N}}_{\text {super }}=135, \mathrm{CV}\right.$ $=0.16$ ) to calculate $N_{\text {MIN }}$. Results from the PBR analyses indicated that the local unit of Bryde's whales in the Hauraki Gulf could not sustain mortality of more than 1 whale $\mathrm{yr}^{-1}$ (abundance of 135 whales $\left[N_{\mathrm{MIN}}=\right.$ $118], \mathrm{CV}=0.16$; recovery factor $=0.5$, maximum rate of increase $=0.04$ ).

\section{DISCUSSION}

In New Zealand, Bryde's whales are listed as 'nationally critical', and globally as Data Deficient (IUCN; Baker et al. 2010). The Hauraki Gulf is an important habitat for the species (Wiseman 2008,
Wiseman et al. 2011), but it is also a region of high shipping transit, which results in whale mortality caused by vessel-strike injuries (Stockin et al. 2008, Wiseman 2008, Behrens 2009, Riekkola 2013, Constantine et al. 2015). Our estimates are precise, robust to the assumptions of the models and could be used in the future to examine population trajectories over time and the impact of ship strikes on the longterm persistence of the population.

\section{Site fidelity and occurrence}

Examination of individual site fidelity patterns suggested that some whales changed their use of the Hauraki Gulf over time. Overall, 28\% of the whales $(n=20)$ were sighted across the 2 survey periods (8 yr). Most whales presented low MSR and SSR ratios, suggesting low site fidelity, with the exception of a few whales that showed moderate values. This 
indicates that the area is an important habitat for some whales. However, site fidelity patterns are not static and change over time, possibly due to responses to environmental conditions, prey availability, age-class and/or reproductive status (Switzer 1993, Hauser et al. 2007, Foote et al. 2010, Barnett et al. 2011). During the course of this study, 13 whales were sexed as females and 3 whales were sexed as males based on molecular identification (Wiseman 2008) and/or on photographs of the whales in close association with young calves. Interestingly, the 3 males identified by Wiseman during 2004 to 2006 were not resighted during 2011 to 2013. It is possible that the whales were in the area but were not identified (i.e. if the notch changed and the whale was misidentified), that they were in the area but not photographed or alternatively, they were absent. Wider genetic sampling of naturally marked whales would allow investigation of potential differences in habitat use by each sex.

The Hauraki Gulf is used by Bryde's whales for both calving and feeding (Wiseman et al. 2011). Approximately the same number of whales visited the area over time; however, the identity of these individuals changed between periods, with the exception of a few whales that continued using the area. It is unknown where these whales go when they leave the area or the reasons that motivate changes in site fidelity over time.

The differences in TER between study periods suggested higher rates in the earlier period during winter months (June to August; Wiseman et al. 2011). However, no significant differences were found among average seasonal TER values, despite higher values obtained during spring 2011 to 2013. In addition, abundance varied between sampling occasions but there was no evidence of seasonality. In contrast, Wiseman et al. (2011) found a seasonal pattern, with higher TER values during winter. Behrens (2009) reported a peak in sightings during autumn and fewer sightings during summer, but this result was not statistically significant. A more recent study found annual but not seasonal changes in the relative density of Bryde's whales in the Hauraki Gulf (Dwyer et al. 2016), and it was noted that inter-annual fluctuations could be explained by climate-driven systems such as El Niño or La Niña. Along the California Bight (USA), Bryde's whale occurrence increased between 2000 and 2010. This increase was driven by changes in prey availability that were affected by seasonal and inter-annual changes in climate and oceanographic conditions (Kerosky et al. 2012). In the southwestern Gulf of California, higher occur- rences of Bryde's whales were observed during La Niña conditions. In contrast, fewer whales were recorded during El Niño and neutral conditions, suggesting that changes in occurrence in that region relate to El Niño-Southern Oscillation inter-annual variability and are probably mediated by prey availability (Salvadeo et al. 2011). Continued monitoring of Bryde's whale abundance, distribution and site fidelity using photo-identification is required to provide a longitudinal dataset of individual whales to evaluate potential effects of inter-annual climate variability in New Zealand waters. This should be conducted in conjunction with aerial surveys that currently provide abundance, though not site fidelity, information for this local population.

\section{Population abundance, migration and apparent survival}

We estimated the number of whales in the Hauraki Gulf across almost a decade of surveys using both the RD and POPAN population models across seasons. The RD approach takes into account temporary emigration, whereas POPAN estimates the total number of animals that visited the area. Both approaches are suited for open populations with heterogeneous data resulting from unequal capture probabilities (Amstrup et al. 2005). Abundance estimates with the RD varied between sampling periods but did not present a seasonal pattern. Temporary emigration rates were fairly consistent between periods (57\% during 2004 to 2006 and $61 \%$ during 2011 to 2013), indicating that approximately half of the whales leave the Hauraki Gulf every season before subsequently returning.

Wiseman (2008) estimated abundance using closed and open methods. The closed estimates were larger than our estimates and also presented broader confidence intervals (e.g. 128 whales estimated during summer); therefore, the closed estimates are deemed imprecise. Estimates of abundance with open models resulted in 46 whales $\mathrm{yr}^{-1}(95 \% \mathrm{CI}=39-53)$. While this estimate is somewhat comparable to our POPAN estimates (for 2004 to 2006: 38-74 and 2011 to 2013: 42-68 whales), ours are seasonal as opposed to annual estimates.

In our study, the differences between POPAN and the RD estimates may be due to the fact that the $\mathrm{RD}$ incorporates an estimate for temporary emigration, allowing individuals to move in and out of the study area between occasions, modelling heterogeneity and resulting in less biased estimates. 
The estimated apparent survival for Bryde's whales (0.878) is lower than survival estimates for humpback whales Megaptera novaeangliae (0.93-0.98; Chaloupka et al. 1999, Perrin et al. 2009, Ashe et al. 2013). POPAN assumes that animals that left the study area died and/or emigrated (confounded parameter), which may result in an underestimate of apparent survival. Since the Hauraki Gulf represents only a small part of a wider range for the New Zealand Bryde's whale population, it is clear that emigration is significant. Nevertheless, mortality should not be underestimated. Vessel strikes have been reported as a major cause of mortality for Bryde's whales in the area (Constantine et al. 2015), and the lower apparent survival estimated here may be reflecting this mortality.

Constantine et al. (2015) estimated that a minimum average of 2.3 whales $\mathrm{yr}^{-1}$ have died as a result of vessel-strike injuries in the Haruaki Gulf since 1996. Results from our PBR analysis suggest that the local unit of Bryde's whales could not sustain the removal of more than 1 whale $\mathrm{yr}^{-1}$ combining all sources of mortality. For this reason, it is imperative that appropriate management measures are instigated to avoid mortalities due to anthropogenic causes.

\section{CONCLUSIONS}

Individual photo-identification studies allow finescale demographic analysis and provide valuable information for the long-term management of populations. Our results provide the first analysis of longterm site fidelity and estimates of apparent survival for Bryde's whales in the Hauraki Gulf using photoidentification methods. We estimated that less than 50 whales visit the Hauraki Gulf during each season (RD estimates), with an estimated apparent survival of 0.88 . Despite long-term site fidelity being detected for 20 whales across an 8 yr period, we report individual changes in the use of the region by whales over time that has, until now, gone undetected. While it is acknowledged that the Hauraki Gulf forms only a part of the known home range for Bryde's whales, it still appears that this region is of importance to the local population-especially to those whales that display moderate site fidelity. It is currently unknown where the whales go when leaving the Hauraki Gulf. However, our findings highlight the need for continuous, as opposed to intermittent, photo-identification studies of Bryde's whales in the region so that fluctuations in abundance, movements, female reproductive rates, individual patterns of residency and habitat use can be monitored over time.
Acknowledgements. This research was funded by the Hauraki Gulf Research Fund administered by the Department of Conservation (Auckland Conservancy). N.W. was supported by a fellowship from Auckland Whale and Dolphin Safari, under director Mark Draskovich. We are particularly indebted to the staff and crew of 'Dolphin Explorer' and Martin Stanley, Liz Brookes, Stephanie Watts, Thelma Wilson, Jonathan Miles and Andrew Baxter (Department of Conservation) for their support of this study. Thanks to all the volunteers and colleagues who assisted us at the CoastalMarine Research Group (Massey University). This research was conducted under contract 1218763 for the Department of Conservation (G.T.P.).

\section{LITERATURE CITED}

Amstrup SC, McDonald TL, Manly BFJ (2005) Handbook of capture-recapture analysis. Princeton University Press, Princeton, NJ

Ashe E, Wray J, Picard CR, Williams R (2013) Abundance and survival of Pacific humpback whales in a proposed critical habitat area. PLOS ONE 8:e75228

Baker A, Madon B (2007) Bryde's whales (Balaenoptera cf. brydei Olsen 1913) in the Hauraki Gulf and northeastern New Zealand waters. Sciences for Conservation 272. Department of Conservation, Wellington

* Baker CS, Lukoschek V, Lavery S, Dalebout ML, Yong-un M, Endo T, Funahashi N (2006) Incomplete reporting of whale, dolphin and porpoise 'bycatch' revealed by molecular monitoring of Korean markets. Anim Conserv 9:474-482

Baker CS, Chilvers BL, Constantine R, DuFresne S, Mattlin R, Van Helden A, Hitchmough R (2010) Conservation status of New Zealand marine mammals (suborders Cetacea and Pinnipedia). N Z J Mar Freshw Res 44:101-115

Baker CS, Chilvers BL, Childerhouse S, Constantine R and others (2016) Conservation status of New Zealand marine mammals. New Zealand Threat Classification Series 14. Department of Conservation, Wellington

Barnett A, Abrantes KG, Stevens JD, Semmens JM (2011) Site fidelity and sex-specific migration in a mobile apex predator: implications for conservation and ecosystem dynamics. Anim Behav 81:1039-1048

Behrens S (2009) Bryde's whales (Balaenoptera brydei) in the Hauraki Gulf and the effects of vessel traffic. MSc thesis, The University of Auckland

Behrens S, Constantine R (2008) Large whale and vessel collisions in northern New Zealand. Paper SC/60/BC9, Scientific Committee of the International Whaling Commission. International Whaling Commission, Santiago

Blackmer AL, Anderson DR, Whitehead H (2000) Temporal variability in features used to photo-identify humpback whales (Megaptera novaeangliae). Mar Mamm Sci 16: 338-354

Burnham KP, Anderson DR, White GC, Brownie C, Pollock KH (1987) Design and analysis of fish survival experiments based on release-recapture data. American Fisheries Society Monographs 5, Bethesda, MD

* Cagnazzi DDB, Harrison PL, Ross GJB, Lynch P (2011) Abundance and site fidelity of Indo-Pacific humpback dolphins in the Great Sandy Strait, Queensland, Australia. Mar Mamm Sci 27:255-281

Chaloupka M, Osmond M, Kaufman G (1999) Estimating seasonal abundance trends and survival probabilities of 
humpback whales in Hervey Bay (east coast Australia). Mar Ecol Prog Ser 184:291-301

Choquet R, Reboulet AM, Lebreton JD, Gimenez O, Pradel R (2005) U-CARE 2.2 user's manual. CEFE, Montpellier Constantine R, Johnson M, Riekkola L, Jervis S, KozmianLedward L, Dennis T (2015) Mitigation of vessel-strike mortality of endangered Bryde's whales in the Hauraki Gulf, New Zealand. Biol Conserv 186:149-157

Cooch E, White BN (eds) (2011) Program MARK: a gentle introduction. Colorado State University, Fort Collins, CO

Crosbie SF, Manly BFJ (1985) Parsimonious modelling of capture-mark-recapture studies. Biometrics 41:385-398

Dwyer S (2014) Spatial ecology and conservation of cetaceans using the Hauraki Gulf, New Zealand. PhD thesis, Massey University, Auckland

Dwyer SL, Clement DM, Pawley MDM, Stockin K (2016) Distribution and relative density of cetaceans in the Hauraki Gulf, New Zealand. NZJ Mar Freshw Res 50: $457-480$

Foote AD, Similä T, Víkingsson GA, Stevick PT (2010) Movement, site fidelity and connectivity in a top marine predator, the killer whale. Evol Ecol 24:803-814

Friday N, Smith TD, Stevick PT, Allen J (2000) Measurement of photographic quality and individual distinctiveness for the photographic identification of humpback whales, Megaptera novaeangliae. Mar Mamm Sci 16:355-374

* Hauser DDW, Logsdon MG, Holmes EE, VanBlaricom GR, Osborne RW (2007) Summer distribution patterns of southern resident killer whales Orcinus orca: core areas and spatial segregation of social groups. Mar Ecol Prog Ser 351:301-310

Huggins RM (1991) Some practical aspects of a conditional likelihood approach to capture experiments. Biometrics 47:725-732

* Hurlbert SH (1984) Pseudoreplication and the design of ecological field experiments. Ecol Monogr 54:187-211

Jolly GM (1965) Explicit estimates from capture-recapture data with both death and immigration-stochastic model. Biometrika 52:225-247

Kasuya T (2002) Japanese whaling. In: Perrin WF, Würsig B, Thewissen JGM (eds) Encyclopedia of marine mammals. Academic Press, San Diego, CA, p 655-662

Kato H (2002) Bryde's whales: Balaenoptera edeni and B. brydei. In: Perrin WF, Würsig B, Thewissen JGM (eds) Encyclopedia of marine mammals. Academic Press, San Diego, CA, p 171-177

Kendall WL, Nichols JD, Hines JE (1997) Estimating temporary emigration using capture recapture data with Pollock's robust design. Ecology 78:563-578

Kerosky SM, Širović A, Roche LK, Baumann-Pickering S, Wiggins SM, Hildebrand JA (2012) Bryde's whale seasonal range expansion and increasing presence in the Southern California Bight from 2000 to 2010. Deep Sea Res I 65:125-132

Kershaw F, Leslie MS, Collins T, Mansur RM and others (2013) Population differentiation of two forms of Bryde's whales in the Indian and Pacific Oceans. J Hered 104: 755-764

Parra G, Corkeron P, Marsh H (2006) Population sizes, site fidelity and residence patterns of Australian snubfin and Indo-Pacific humpback dolphins: implications for conservation. Biol Conserv 129:167-180

Editorial responsibility: Ana Cañadas,

Madrid, Spain
Penry GS (2010) The biology of South African Bryde's whales. PhD thesis, University of St. Andrews

Perrin WF, Thewissen JGM, Würsig B (eds) (2009) Encyclopedia of marine mammals. Academic Press, San Diego, CA

Pollock KH (1982) A capture-recapture design robust to unequal probability of capture. J Wildl Manag 46:752-757

Reilly SB, Bannister JL, Best P, Brown M and others (2008) Balaenoptera edeni. The IUCN Red List of Threatened Species, version 2015.2. IUCN, Gland

Riekkola L (2013) Mitigating collisions between large vessels and Bryde's whales in the Hauraki Gulf, New Zealand. BSc thesis, The University of Auckland

Salvadeo C, Flores-Ramirez S, Gomez-Gallardo A, MacLeod C, Lluch-Belda D, Jaume-Schinkel S, Urban-R J (2011) Bryde's whale (Balaenoptera brydei) in the southwestern Gulf of California: relationship with ENSO variability and prey availability. Cienc Mar 37:215-225

Schwarz CJ, Arnanson AN (1996) A general methodology for the analysis of capture-recapture experiments in open populations. Biometrics 52:860-873

Stanley TR, Burnham KP (1999) A closure test for time-specific capture-recapture data. Environ Ecol Stat 6:197-209

Stevick PT, Palsbøll PJ, Smith TD, Bravington MV, Hammond PS (2001) Errors in identification using natural marking: rates, sources, and effects on capture-recapture estimates of abundance. Can J Fish Aquat Sci 58: 1861-1870

Stockin KA, Wiseman N, Hartman A, Moffat N, Roe WD (2008) Use of radiography to determine age class and assist with the post-mortem diagnostics of a Bryde's whale (Balaenoptera brydei). NZJ Mar Freshw Res 42: 307-313

* Switzer PV (1993) Site fidelity in predictable and unpredictable habitats. Evol Ecol 7:533-555

Committee on Taxonomy (2016) List of marine mammal species and subspecies. Society for Marine Mammalogy, Anacortes, WA. www.marinemammalscience.org (accessed 13 April 2017)

Tezanos-Pinto G, Constantine R, Brooks L, Jackson J, Mourão F, Wells S, Baker CS (2013) Decline in local abundance of bottlenose dolphins (Tursiops truncatus) in the Bay of Islands (New Zealand). Mar Mamm Sci 29: E390-E410

*Wada S, Oishi M, Yamada TK (2003) A newly discovered species of living baleen whale. Nature 426:278-281

Wade P (1998) Calculating limits to the allowable humancaused mortality of cetaceans and pinnipeds. Mar Mamm Sci 14:1-37

Williams BK, Nichols JD, Conroy MJ (2002) Analysis and management of animal populations. Academic Press, San Diego, CA

* Wilson B, Hammond PS, Thompson PM (1999) Estimating size and assessing trends in a coastal bottlenose dolphin population. Ecol Appl 9:288-300

Wiseman N (2008) Genetic identity and ecology of Bryde's whales in the Hauraki Gulf, New Zealand. PhD thesis, The University of Auckland

Wiseman N, Parsons S, Stockin K, Baker CS (2011) Seasonal occurrence and distribution of Bryde's whales in the Hauraki Gulf, New Zealand. Mar Mamm Sci 27: E253-E267

Submitted: November 8, 2016; Accepted: May 12, 2017 Proofs received from author(s): June 30, 2017 